\title{
LESIONES TRAUMÁTICAS RECIENTES EN CASOS DE VIOLENCIA FAMILIAR
}

\section{RECENT TRAUMATIC LESIONS IN CASES OF FAMILY VIOLENCE}

\author{
José Pacheco $0^{1,2, a}$, Noelia Díaz ${ }^{2, b}$, Nancy de La Cruz ${ }^{1, c}$
}

La violencia familiar, como problema emergente en salud pública, genera un necesario análisis multidisciplinario que incluye la participación de profesionales de la salud y del derecho, sobre todo en los casos en que las víctimas con lesiones físicas hayan denunciado el hecho ante las autoridades competentes.

En las diferentes instituciones del sector salud del Perú, los médicos reciben y asisten diariamente a personas con traumatismos ocasionados por agresiones intradomiciliarias. Por otra parte, las autoridades policiales, fiscal o judicial solicitan a los médicos una descripción detallada de las lesiones con la respectiva identificación de los agentes causantes (objetos contundentes, arma blanca, etc.). Cabe resaltar que, posteriormente, también será necesario establecer los daños psicológicos y el impacto social de este tipo de violencia, como lo han descrito diferentes estudios $(1,2)$.

Todo médico, tenga o no especialidad en el área clínica o quirúrgica, deberá conocer cuáles son las

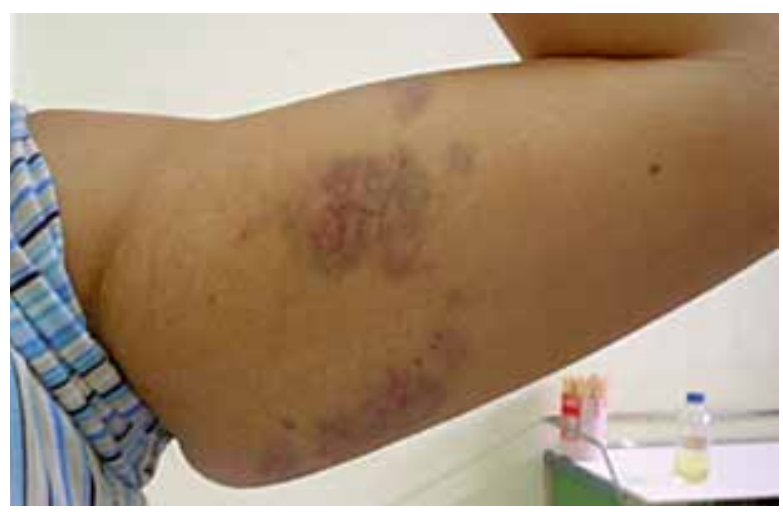

Figura 1. Víctima de violencia familiar. Equimosis violácea en brazo izquierdo ocasionada por presión de un objeto contundente. Se observa la forma del agente causante (dedos de la mano del agresor). características de las diversas lesiones traumáticas que se presentan en víctimas de violencia familiar, quienes a veces acuden a los servicios de urgencias ${ }^{(3)}$. Del mismo modo, si la autoridad lo requiere, el médico deberá emitir un informe específico que incluya una valoración y cuantificación de las lesiones en días de incapacidad, dato muy importante para que el fiscal formalice la denuncia pero ante el juez, o de lo contrario, disponga el archivo definitivo de la investigación del delito.

Los médicos de instituciones de salud pública, generalmente de los lugares más distantes de las capitales provinciales, también deberán saber cuál es la proyección legal y social de su evaluación, ya que en la legislación

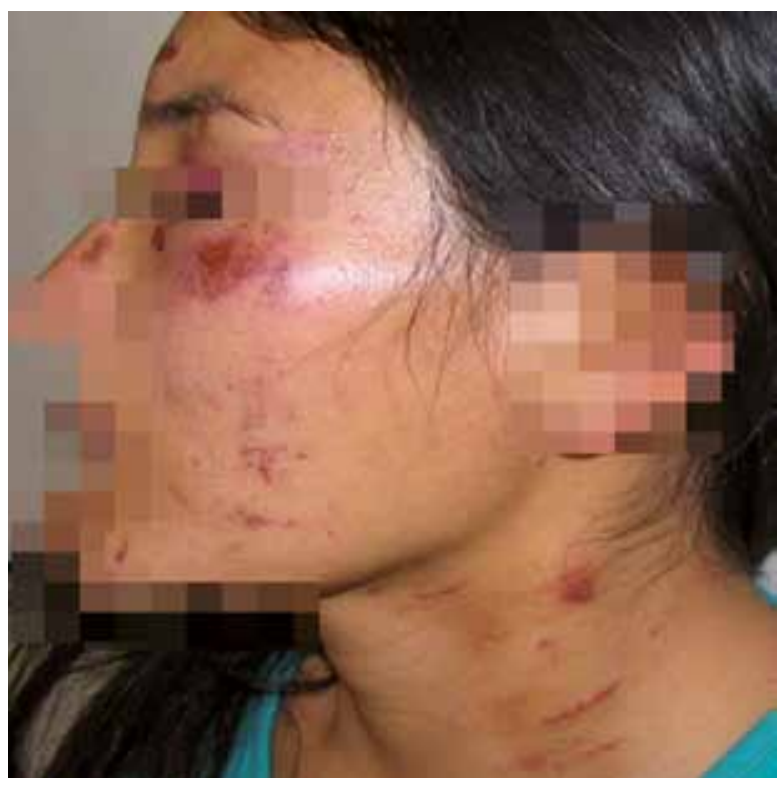

Figura 2. Víctima de violencia familiar. Se observan tumefacciones y excoriaciones recientes en el rostro. Estas lesiones fueron ocasionadas por la acción de un objeto contundente y la fricción sobre la superficie de la piel.

\footnotetext{
Facultad de Medicina Humana, Universidad Nacional Mayor de San Marcos. Lima, Perú

Ministerio Público. Lima, Perú

Médico, especialista en Medicina legal, magíster en Salud Pública, doctor en Derecho; ${ }^{\mathrm{b}}$ abogada, fiscal adjunta superior penal; ${ }^{\mathrm{c}}$ médico especialista en Medicina legal, magíster en docencia universitaria
} 
peruana, por ejemplo, se establece como obligación la certificación de lesiones traumáticas en ausencia de un médico legista ${ }^{(4)}$, así como la notificación a la autoridad competente como ya está normado en otros países ${ }^{(5)}$, previa capacitación del personal en la identificación e informe de la violencia doméstica ${ }^{(6)}$.

Legalmente en el Perú, y según el caso, el resultado de esta evaluación médica generará la posterior tipificación de lesiones leves o graves por parte del juez con la consecuente sentencia al agresor, acción judicial que a veces es tan esperada y reclamada por nuestra sociedad.

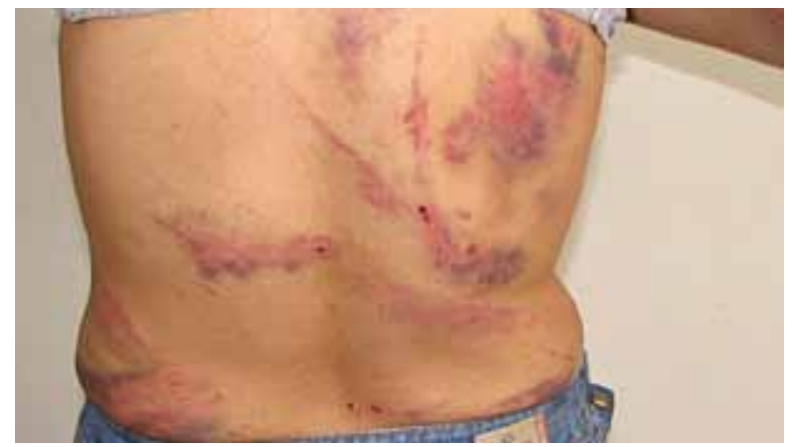

Figura 3. Víctima de violencia familiar. Se observan excoriaciones recientes múltiples en región torácica posterior derecha y regiones lumbares. Estas lesiones fueron ocasionadas por el impacto y arrastre por el suelo por parte del conviviente.

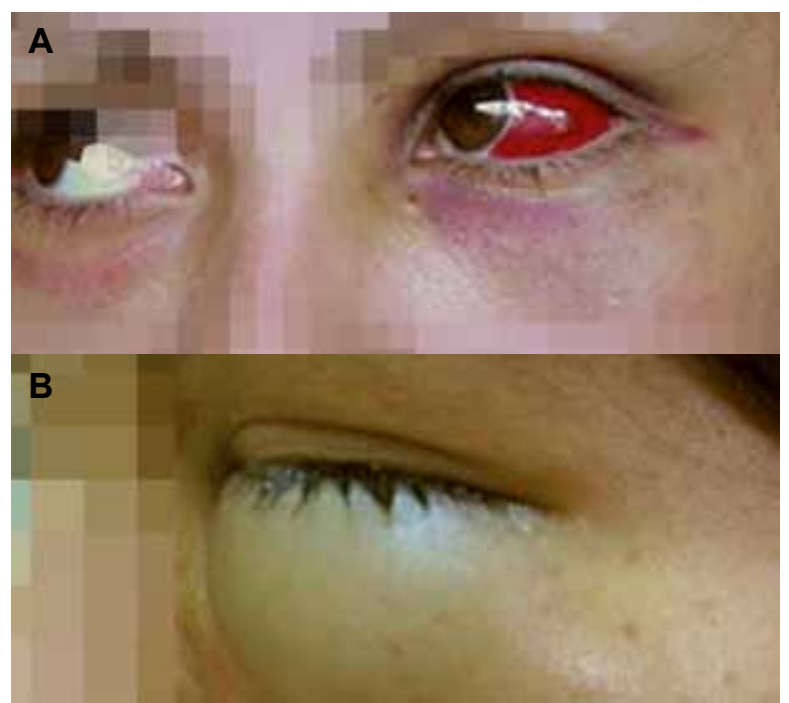

Figura 4. Víctima de violencia familiar. A. Se observa una hemorragia subconjuntival en ojo izquierdo ocasionada por el impacto del puño derecho del agresor. La presencia de equimosis violáceas en las regiones perioculares indican la cronología del suceso (de 2 a 3 días aprox.). B. Se observa un amplio hematoma ocasionado también por un puño. Esta lesión se produce por una acción más violenta con la ruptura de vasos sanguíneos de mayor calibre en comparación con las equimosis. Aquí es necesaria la evaluación de un médico oftalmólogo.
A continuación se presentan imágenes de diversos tipos de lesiones a fin de que la comunidad médica diferencie cada una de las más frecuentes y, sobre todo, para que la sociedad conozca cuál es la magnitud del daño físico en las víctimas de violencia familiar de ambos sexos y de diferentes grupos de edad, dentro de las investigaciones de delitos contra la vida, el cuerpo y la salud que exige la justicia ${ }^{(7)}$.

Estas imágenes corresponden al archivo personal de los autores, y fueron obtenidas de personas que acudían por solicitud de una autoridad para una evaluación especializada; a todas las personas se les solicitó su consentimiento para ser fotografiadas, e informó que estas fotografías no formarían parte del archivo legal de su caso sino que se emplearían con fines docentes.

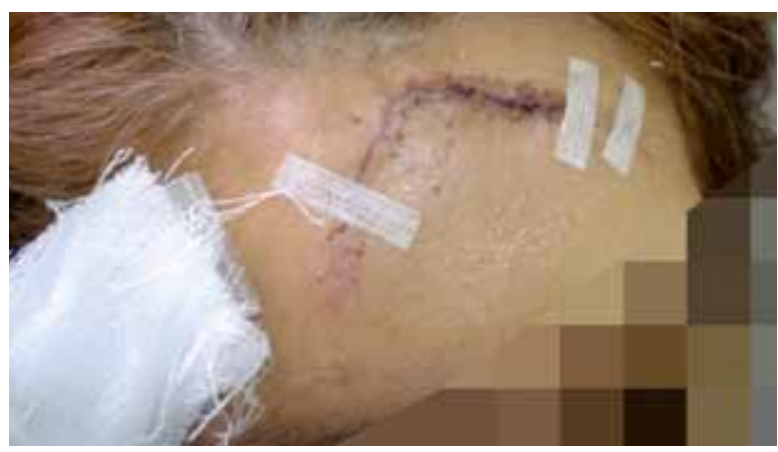

Figura 5. Víctima de violencia familiar. Se observa una Herida contusa en forma de "c" invertida con signos de sutura anterior. Esta lesión, por presentarse como un colgajo, requirió varios días de incapacidad médico legal constituyéndose legalmente en un delito.

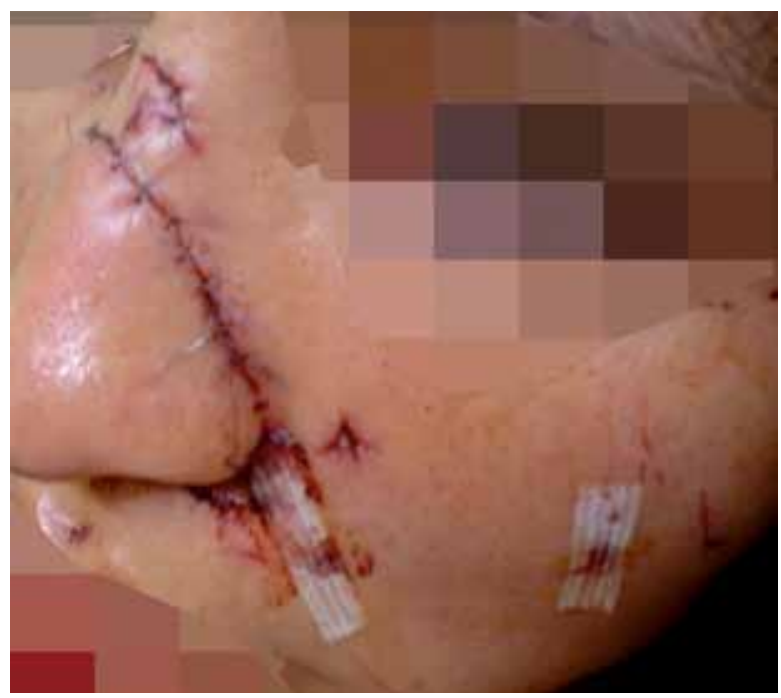

Figura 6. Víctima de violencia familiar. Se observa una extensa herida cortante suturada en el rostro. Esta lesión también requirió más de diez días de incapacidad médico legal constituyéndose legalmente en un delito. 


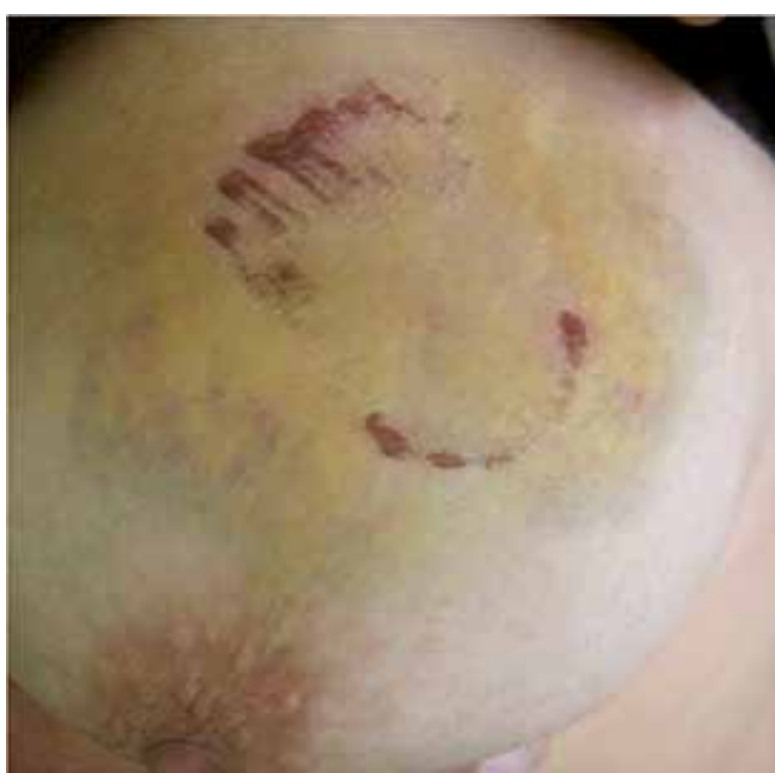

Figura 7. Víctima de violencia familiar. Se observa una lesión ocasionada por mordedura humana en la región mamaria. Las excoriaciones costrosas dibujan las arcadas dentarias.

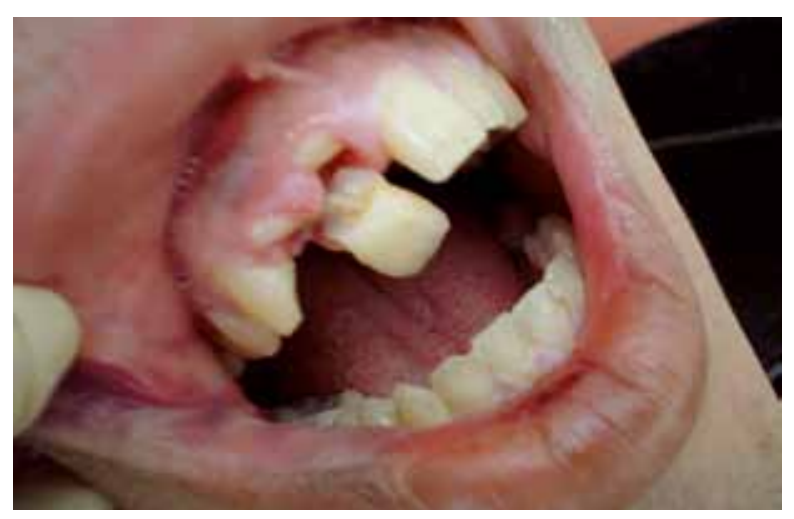

Figura 8. Víctima de violencia familiar. Se observa una avulsión traumática de pieza dentaria por una contusión en cavidad oral. Aquí fue necesaria la evaluación e informe odontológico para la posterior tipificación legal de la lesión.

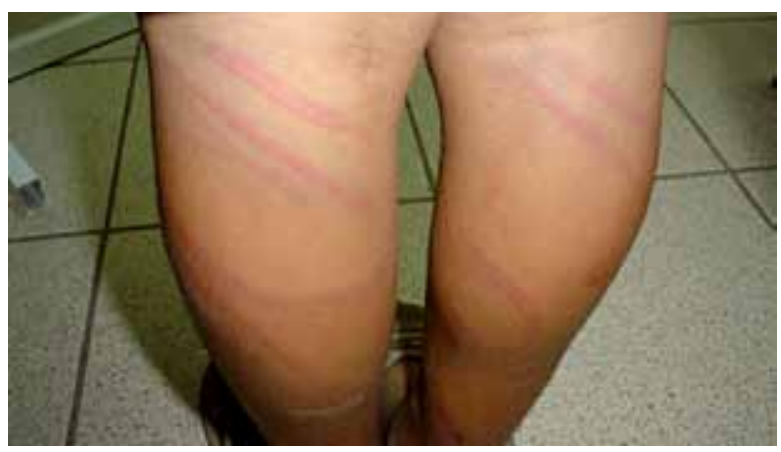

Figura 9. Víctima de violencia familiar. Menor de edad que fue castigado por su padre. Se observa equimosis lineales que dibujan la forma del agente lineal flexible en cara posterior de ambas piernas ("correazos").

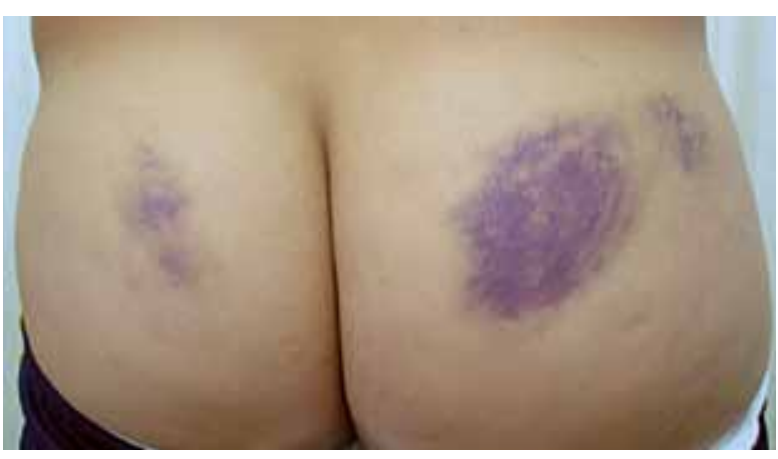

Figura 10. Víctima de violencia familiar. Menor de edad que fue agredido por su hermano. Se observan equimosis violáceas azuladas en regiones glúteas, típicas en las "patadas" (forma casi exacta de la suela de un calzado).

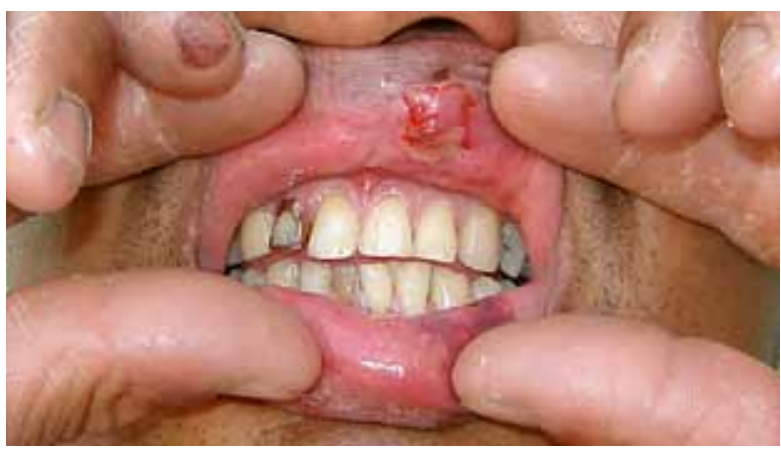

Figura 11. Víctima de violencia familiar. Hombre con una contusión en la boca que fue ocasionada por su conviviente. Se observa una erosión amplia en mucosa labial superior por la resistencia e impacto con los dientes.

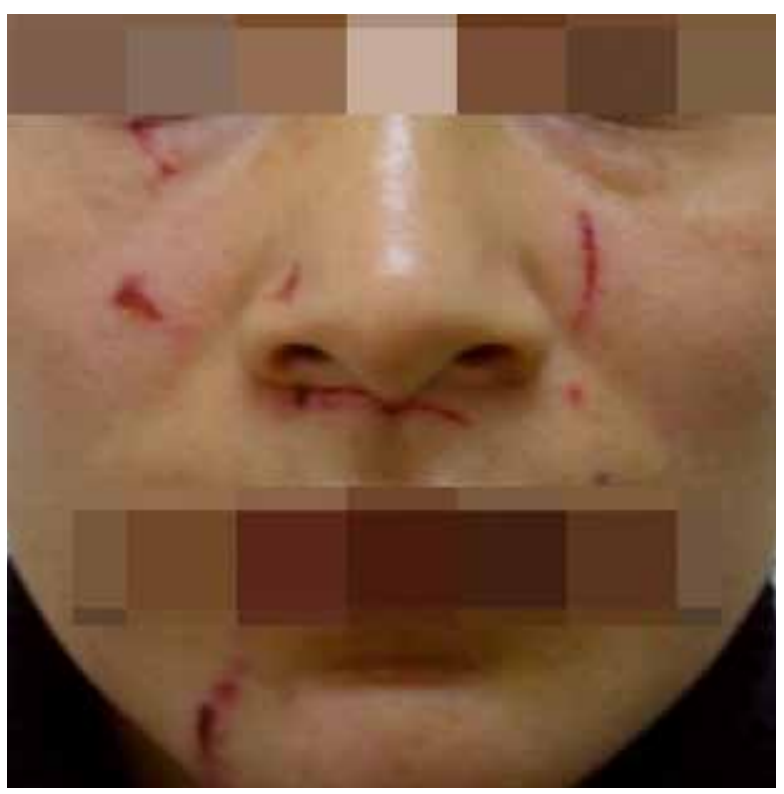

Figura 12. Víctima de violencia familiar. Mujer que fue agredida por su hija adolescente. Se observan múltiples excoriaciones en el rostro ocasionadas por las uñas de una mano humana (típicos "arañazos"). 


\section{REFERENCIAS BIBLIOGRÁFICAS}

1. Valdez R, Juárez $C$. Impacto de la violencia doméstica en la salud mental de las mujeres: análisis y perspectivas en México. Salud Mental. 1998;21(6):1-10.

2. Hernández D. Pobreza urbana y violencia doméstica en hogares de la Ciudad de México. Acta Sociol. 1998;22:25-43.

3. McLeer SV, Anwar R. A study of battered women presenting in an emergency department. Am J Public Health. 1989;79(1):65-6.

4. Código de Procedimientos Penales. Ley 4019. Art. $1611^{\circ}$. Nombramiento de Peritos. Preferencia y honorarios. Lima Perú (23 de noviembre del 1939).

5. Diario Oficial de la Federación. Norma Oficial Mexicana NOM-190-SSA1-1999. Prestación de servicios de salud. Criterios para la atención médica de la violencia familiar. México, DF: Secretaría de Salud; 2000.
6. Muñiz M, Ferrer D, González J, Jiménez Y. Violencia intrafamiliar: su presentación en un área de salud. Rev Cubana Med Gen Integr 2000;16(5):468-73.

7. Código Penal. Decreto Legislativo N. ${ }^{\circ} 635$. Art. 121-122. ${ }^{\circ}$. Delitos contra la vida, el cuerpo y la salud. Lesiones.; Perú, 1991.

Correspondencia: José Luis Pacheco de la Cruz Dirección: Av. Alfonso Ugarte 848, Lima 1, Perú. Teléfono: (511) 4234319

Correo electrónico: jp_cienciasforenses@hotmail.com

\section{Suscríbase en forma electrónica y gratuita a los contenidos de la Revista Peruana de Medicina Experimental y Salud Pública, ingrese a WWW.ins.gob.pe, seleccione el ícono de la revista y envíenos sus datos.}
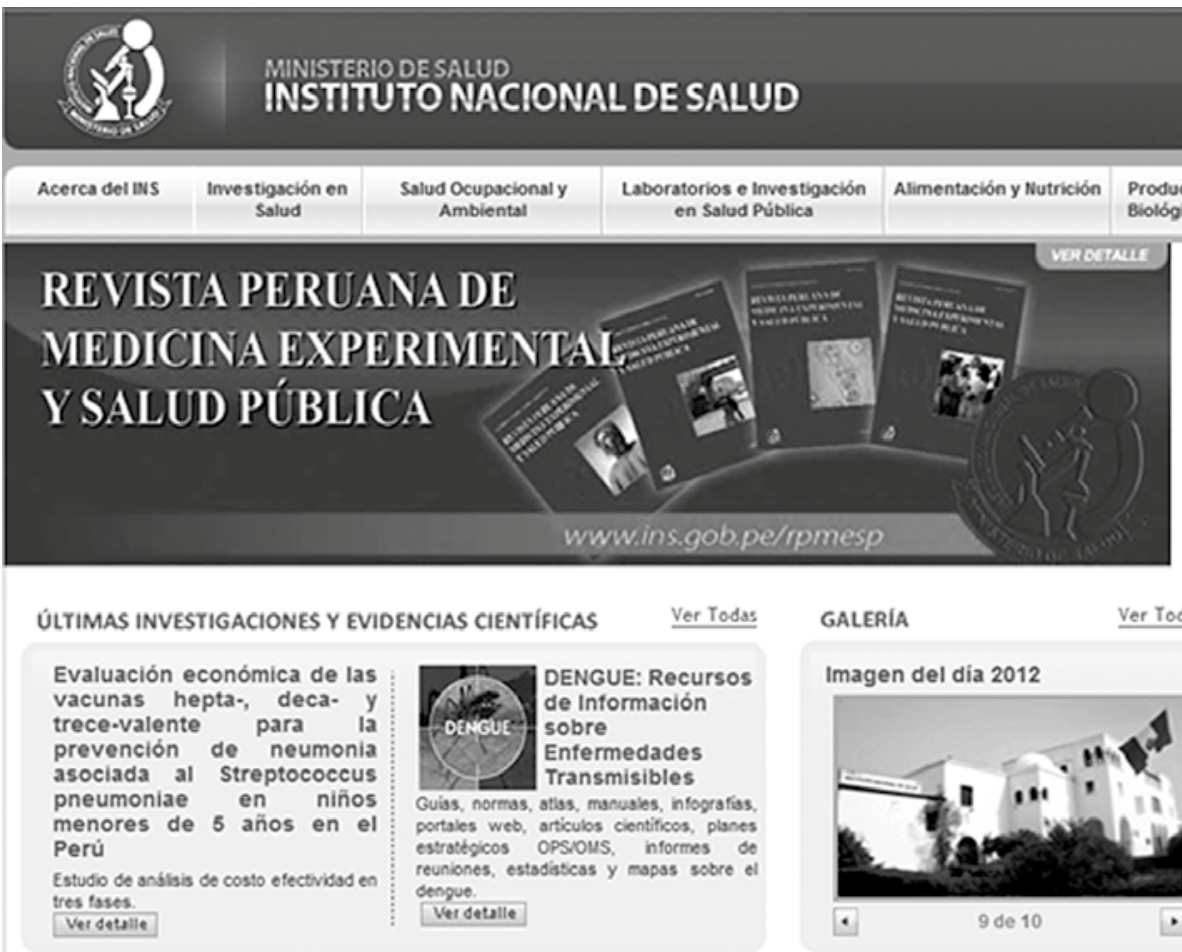

GALERIA

Ver Todss

Imagen del dia 2012

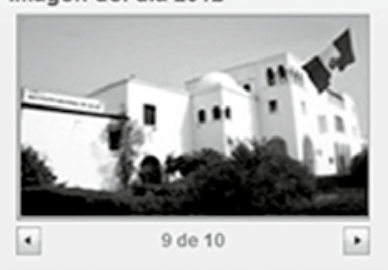

Buscar. 